\title{
Disordered gastric motor function in diabetes mellitus
}

\author{
M.Horowitz, R. Fraser \\ Department of Medicine, Royal Adelaide Hospital, North Terrace, Adelaide, Australia
}

\begin{abstract}
Summary The application of novel investigative techniques has demonstrated that disordered gastric motility occurs frequently in diabetes mellitus. Gastric emptying is abnormal in about $50 \%$ of diabetic patients and delay in gastric emptying of nutrient-containing meals is more common than rapid emptying. The blood glucose concentration influences gastric motility in diabetes. In IDDM patients, gastric emptying is retarded during hyperglycaemia and may be accelerated by hypoglycaemia. Gastroparesis therefore does not necessarily reflect irreversible autonomic neuropathy and blood glucose concentrations must be monitored when gastric motility is evaluated in diabetic patients. There is a poor relationship between gastric emptying
\end{abstract}

and gastrointestinal symptoms and the mechanisms by which abnormal motility causes symptoms are unclear. The introduction of new gastrokinetic drugs has improved therapeutic options for the management of symptomatic patients with gastroparesis considerably. The contribution of disordered gastric emptying to poor glycaemic control is unclear, but the demonstration that the rate of gastric emptying is a major factor in normal blood glucose homeostasis suggests that this is likely to be significant. [Diabetologia (1994) 37: 543551]

Key words Gastric motility, gastric emptying, fundus, antrum, pylorus, radioisotopic methods.
Recent observations support the concept that abnormal gastric motor function has a major impact on the management of patients with diabetes mellitus. Disordered gastric motility due to diabetic gastroenteropathy is probably the most common cause of chronic gastroparesis [1]. Symptomatic diabetic gastroparesis is amongst the most incapacitating of all diabetic complications. A further, and possibly more important, rationale for treatment of disordered gastric emptying in diabetes is to improve the control of blood glucose concentrations.

\footnotetext{
Corresponding author: Associate Professor M.Horowitz, Department of Medicine, Royal Adelaide Hospital, North Terrace, Adelaide 5000, Australia
}

Abbreviations: IDDM, insulin-dependent diabetes mellitus; NIDDM, non-insulin-dependent diabetes mellitus

\section{Prevalence and natural history}

"I believe that this syndrome - gastroparesis diabeticorum - is more often overlooked than diagnosed." Kassander (1958)

Rundles in 1945 [2] was the first to clearly document the association between delayed gastric emptying and diabetes, although in 1937 Ferroir observed: "X ray examination showed that in diabetes the stomach ... motor responses are weaker than normal and die out quickly" [3]. The descriptive term "gastroparesis diabeticorum" was coined by Kassander in 1958 [4]. Disordered gastric motility was thought until recently to be a relatively infrequent complication of diabetes $[2,5]$. However, cross-sectional studies have demonstrated that gastric emptying of solid, or nutrient liquid meals is delayed in about $50 \%$ of diabetic patients [69]. The prevalence of delayed gastric emptying in IDDM and NIDDM is probably similar (Fig. 1) [6-8]. Retardation of gastric emptying is often associated 

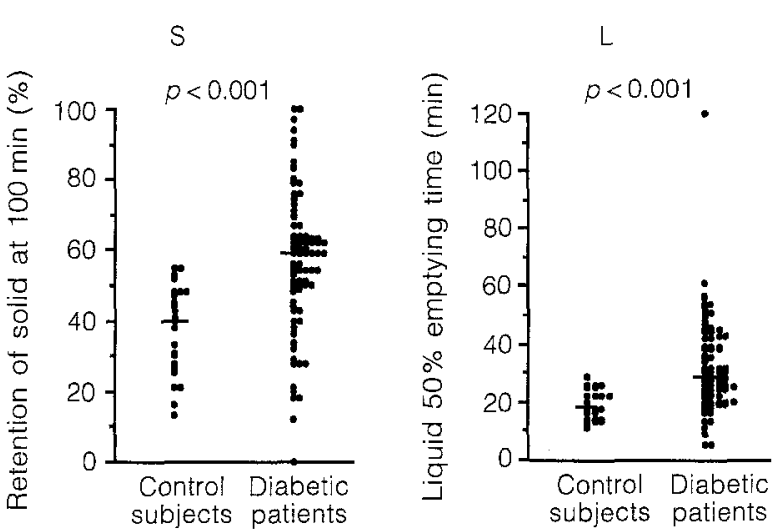

Fig. 1. Gastric emptying expressed as the amount of a solid meal (S) $\left(100 \mathrm{~g}{ }^{99 \mathrm{~m}} \mathrm{Tc}-m i n c e d\right.$ beef) remaining in the stomach at 100 min after meal completion and the $50 \%$ emptying time for a liquid meal (L) (150 ml ${ }^{113 \mathrm{~m} I n-D T P A ~} 10 \%$ dextrose) in 87 randomly-selected out-patients with diabetes (67 IDDM, 20 NIDDM) and 25 normal volunteers. Gastric emptying of the solid meal is slower than the upper limit (mean $\pm 2 \mathrm{SD}$ ) of the normal range in $34 \%$ of the diabetic patients and more rapid in one. Liquid emptying is delayed in $45 \%$ of the patients and more rapid in $6 \%$. The mean plasma glucose concentration during the gastric emptying measurements was $15.6 \pm 0.6 \mathrm{mmol} / \mathrm{l}$. Horizontal lines represent median values (from Horowitz et al. [7])

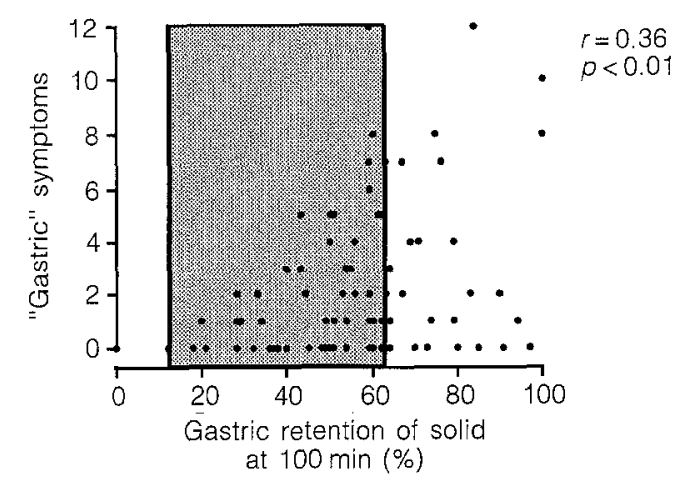

Fig. 2. The relationship $(r=0.36, p<0.01)$ between symptoms referable to delayed gastric emptying and gastric emptying of the solid component of a mixed solid/liquid meal in the same patients included in Figure 1. The normal range for gastric emptying is shown in the shaded area (from Horowitz et al. [7])

with abnormal intragastric distribution of food [10]. Gastric emptying, particularly the "early phase" of liquid emptying, is sometimes faster than normal [7, 11, 12]. A recent study suggests that rapid gastric emptying of nutrient liquids may be characteristic of "early" NIDDM [13]. There is a poor relationship between transit in different regions of the gastrointestinal tract in diabetes [6-8]. It seems likely that the prevalence of gastroduodenal motor abnormalities will be greater than that of disordered gastric emptying [14], but this issue has not been addressed. The prevalence of abnormal gastric emptying during euglycaemia has not been evaluated; in view of the demonstration that hyperglycaemia slows emptying (as will be discussed) it is likely to be less than that reported for diabetic patients in general [6-11]. Studies to evaluate the prevalence of disordered emptying in patients with brittle diabetes are also required.

There is no adequate information about the natural history of disordered gastric motor function in diabetes. It will be important to determine whether the risk is influenced by long-term blood glucose control or genetic factors, which have been implicated in the aetiology of autonomic nerve dysfunction. Although symptomatic diabetic gastroparesis has been considered to be associated with a poor prognosis [5] this assumption may be incorrect [15]. In particular, delay in gastric emptying, like cardiovascular autonomic impairment, is not inevitably a "late" complication of diabetes [7-9].

\section{Clinical manifestations}

"The retention of stomach contents in a diabetic obviously may cause confusion as far as food intake and utilization are concerned." Kassander (1958)

Disordered gastric motility may theoretically cause upper gastrointestinal symptoms, alterations in glycaemic control and changes in oral drug absorption.

\section{Gastrointestinal symptoms}

Although appropriate population-based studies have not been performed there seems little doubt that there is a high prevalence of upper gastrointestinal symptoms in diabetic patients $[7,8,16,17]$. However, the initial expectation that there would be a close concordance between delay in emptying and the presence of symptoms such as nausea, abdominal discomfort and vomiting [4] has not been substantiated. In contrast, the relationship between gastric emptying and gastrointestinal symptoms is relatively poor $[6-9,18-22]$, so that up to $50 \%$ of patients with marked delay in gastric emptying have few, or no upper gastrointestinal symptoms (Fig. 2). These observations have led inevitably to the recognition that while abnormal emptying occurs frequently, its role in the aetiology of gastrointestinal symptoms is unclear. Delayed gastric emptying should therefore be considered as a marker of gastroduodenal motor abnormality, rather than the direct cause of symptoms. Symptoms, which are presumed to result from disordered motility, are likely to be multifactorial in origin. In some patients, they may reflect disordered oesophageal, small intestinal or colonic motility $[7,8$, 16] or arise from psychiatric abnormality [17]. Abnormal gastric myoelectrical activity may play a role, but evidence to support this concept is limited [23]. Abnormal feedback from mucosal sensory afferent receptors in the stomach or small intestine may theoretically cause symptoms [24], but this has not been evaluated. 

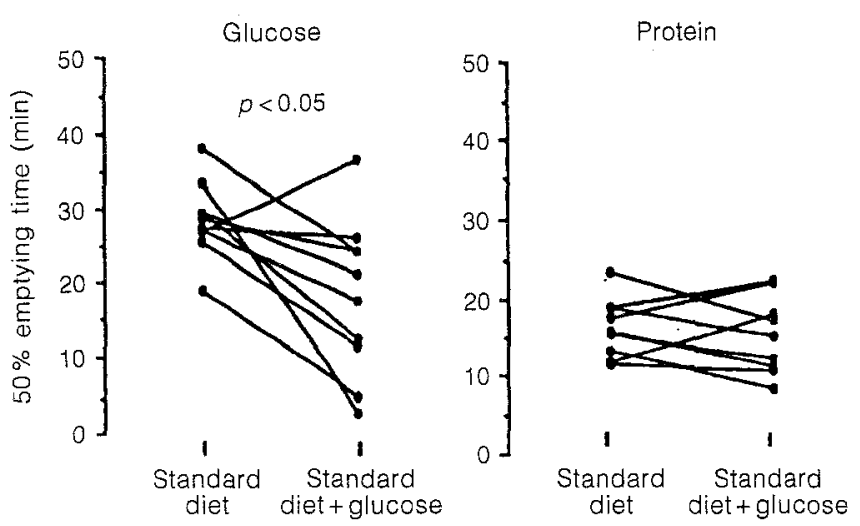

Fig. 3. The effect of dietary supplementation with $440 \mathrm{~g}$ glucose/day for 3 days on gastric emptying ( $50 \%$ emptying time) of $68 \mathrm{~g}$ glucose and a low-nutrient protein drink in normal volunteers. Gastric emptying of glucose is more rapid after glucose supplementation, whereas there is no change in gastric emptying of protein (from Cunningham et al. [31])

\section{Glycaemic control}

The rate of gastric emptying acts as a major factor in blood glucose homeostasis in normal subjects by controlling the delivery of carbohydrate to the small intestine [25-28]. For example, gastric emptying accounts for $34 \%$ of the variance in peak plasma glucose after a 75 -g oral glucose load in normal subjects, so that peak plasma glucose is greater if gastric emptying is more rapid [25]. The alterations in oral glucose tolerance observed in normal subjects as a result of stress are likely to reflect changes in gastric emptying [26]. Because of deficient counter-regulatory responses, factors which modulate gastric emptying in normal subjects, including cigarette smoking and many drugs [1], would be expected to have a major impact on oral glucose tolerance and the glycaemic response to carbohydrate-containing meals in diabetic patients [29-30]. The beneficial effects of high glycaemic index foods and certain forms of fibre on glycaemic control in NIDDM are likely to reflect retardation of gastric emptying [29] as well as slower intestinal carbohydrate absorption.

It has been suggested that gastric emptying of carbohydrate-containing liquids is normally regulated at about $2 \mathrm{kcal} / \mathrm{min}$ as a result of feedback from mucosal receptors in the small intestine [1]. However, recent observations indicate that feedback from these receptors can be influenced by patterns of prior nutrient intake $[31,32]$. For example, in healthy humans gastric emptying of glucose is faster after dietary supplementation with glucose for 3 days (Fig. 3) [31]. Adaptive changes in emptying, which may be specific for certain nutrients, are probably more likely to reflect a decrease in the number or affinity of small intestinal receptors, rather than altered nutrient absorption. It will be important to determine the influence of previous dietary intake on gastric emptying in diabetic patients.
The possibility that abnormalities of gastric emptying, due to irreversible autonomic nerve dysfunction or variations in blood glucose, contribute to poor glycaemic control in diabetes by causing a mismatch between the onset of insulin or oral hypoglycaemic drug action and the absorption of nutrients from the small intestine, has not yet been investigated adequately. Such a relationship would have major implications for the management of patients with poorly-controlled diabetes. It is also possible that delayed gastric emptying could be an advantage, particularly in NIDDM, because carbohydrate may be absorbed more slowly in co-ordination with the delayed insulin release characteristic of this disorder [29-30]. Whether identification of abnormal emptying is likely to improve glycaemic control is perhaps best initially addressed by determining whether pharmacological improvement of delayed gastric emptying has beneficial effects on blood glucose control in IDDM. Theoretically, gastrokinetic drugs will also reduce changes in gastric emptying occurring as a result of alterations in blood glucose, making the delivery of nutrients to the small intestine more predictable.

\section{Oral drug absorption}

Because most drugs are absorbed more slowly from the stomach than the small intestine, gastric emptying is an important determinant of oral drug absorption [1]. However, when oral pharmaceuticals are given chronically changes in gastric emptying would not be expected to have a major influence on steady-state blood concentrations. There is little information about drug absorption in diabetes [33], but it would be surprising if absorption of many drugs, including alcohol, was not slower in patients with gastroparesis. In normal subjects the absorption of glibenclamide correlates with the rate of gastric emptying, and absorption of glipizide is slower during induced hyperglycaemia when compared to euglycaemia $[1,34]$. The latter observation presumably reflects retardation of gastric emptying. Fasting antroduodenal motility may also influence drug absorption. Normal fasting antral motility is cyclical and consists of three phases which have a cycle time of about 100 min: phase 1 - motor quiescence, phase 2 - irregular contractions and phase 3-regular high amplitude contractions at the maximal rate of about 3 per min for approximately $5 \mathrm{~min}[1]$. This activity is not interrupted by intake of small volumes $(<150 \mathrm{ml})$ of non-nutrient liquids (including tablets and capsules) and solid particles greater than $2 \mathrm{~mm}$ in size are usually only emptied when phase 3 occurs in the stomach. Gastric phase 3 activity is absent in many patients with diabetes $[35,36]$ and this could lead to grossly delayed drug absorption. 
$N$

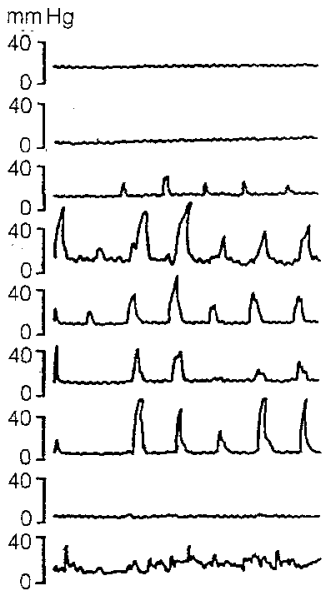

D

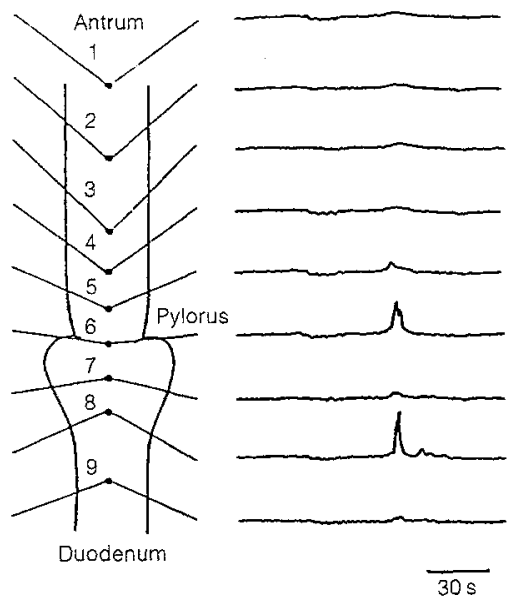

Fig.4. Manometric recording of pressures in the antrum, pylorus and duodenum after ingestion of a solid meal in a normal subject (left) and a diabetic patient with gastroparesis (right). The position of the recording channels is shown. In the normal subject there are a number of antral pressure waves. In the diabetic patient there is evidence of antral hypomotility. The plasma glucose concentration was $15 \mathrm{mmol} / \mathrm{l}$ (from Horowitz and Dent [1])

\section{Diagnosis}

"While the clinical evidence of grossly disturbed gastrointestinal motility in these cases is indisputable, it has been difficult roentgenologically to demonstrate positive findings." Rundles (1945)

Because the predictive value of symptoms is poor $[7,8]$, objective measurement is required for the diagnosis of disordered gastric motility in diabetes. Such measurements should ideally be made during euglycaemia. At a minimum blood glucose concentrations must be monitored. Endoscopy and sometimes barium studies are necessary to exclude gastric outlet, or proximal small intestinal, obstruction and other disorders that may cause non-specific upper gastrointestinal symptoms, such as peptic ulcer and oesophagitis.

A number of techniques are now available to study gastric motility in humans. These methods, which fall into three categories: measurements of gastric emptying (principally scintigraphy, radiology and ultrasound), intraluminal pressure measurements (manometry) and recording of gastric electrical activity using surface electrodes (electrogastrography), have been reviewed elsewhere [1]. Scintigraphic measurement of gastric emptying is at present the most accurate and clinically applicable method. Radionuclide markers are incorporated into meals and a gamma camera is used to record the abdominal distribution of radioactivity. Because the relationship between emptying of solids and liquids is relatively poor, gastric emptying in diabetic patients should ideally be evaluated with a test meal containing discretely labelled solid and nutrient

liquid components [7,11]. Non-nutrient liquids, such as water, which do not stimulate mechanisms which retard gastric emptying, should not be used. The major disadvantage of scintigraphy is that it requires expensive equipment, often with limited availability. Contrast studies using liquid barium should not be used to evaluate gastric emptying, but X-ray evaluation of the emptying of radiopaque markers may be useful [37]. The use of gastropyloroduodenal manometry has provided substantial insights into the physiology of normal gastric emptying and the dysfunctions associated with disordered gastrointestinal motility in diabetes [36-39]. At present this remains a highly specialised technique which is likely to gain acceptance as a clinical procedure.

\section{Gastroduodenal motor dysfunctions - potential causes of disordered gastric emptying}

The mechanical controls of normal gastric emptying are still poorly understood. The traditional concept that tonic contraction of the gastric fundus has the major control over liquid emptying, whilst gastric emptying of solids is dependent on the grinding function of the antrum, has been challenged by the observation that transpyloric flow is mainly pulsatile. Recent studies indicate that the rate of gastric emptying is related to the relationships between contractions generated by the fundus, antrum, pylorus and proximal small intestine [1]. Patterns of postprandial motility are critically dependent on meal composition (i. e. solid, nutrient or non-nutrient liquid) and volume. Localised pyloric contractions appear to play an important role in the regulation of nutrient emptying by acting as a brake $[1,32]$.

In diabetic patients the major emphasis has been on antral motor function, assessed manometrically as a "motility index". The latter measurement takes into account the amplitude and frequency of pressure waves, but provides no information about their spatial or temporal organisation, which are likely to be a major determinant of their mechanical consequences. Most studies have been performed in symptomatic patients who were assumed to have gastroparesis $[14,36]$, but in view of the poor relationship between symptoms and gastric emptying, it is unlikely that all had delayed emptying. Interpretation of previous observations is also hampered by the fact that blood glucose concentrations were often not stabilised, or even monitored, and the position of the manometric catheter was not localized precisely. Because no studies have measured pressures in the proximal stomach, antrum, pylorus and duodenum simultaneously with transpyloric flow, there is considerable uncertainty about the relative contribution of regional abnormalities of motor function to disordered gastric emptying.

Despite these limitations it is clear that abnormalities of both fasting and postprandial motility occur 

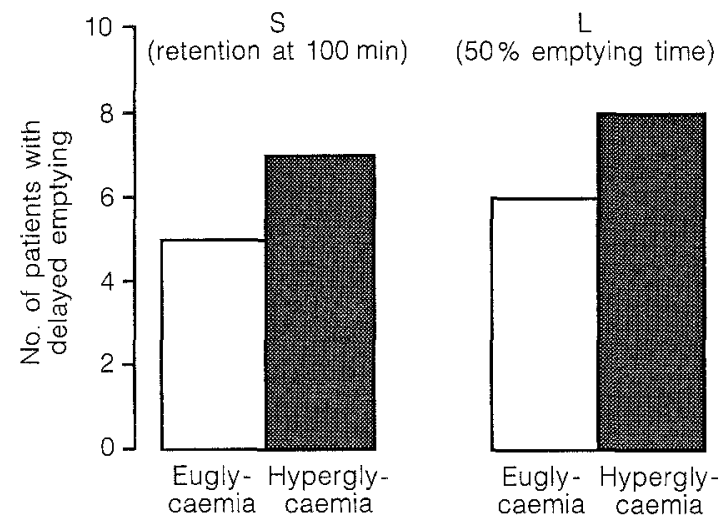

Fig.5. Gastric emptying in 10 IDDM patients during euglycaemia (plasma glucose $4-8 \mathrm{mmol} / \mathrm{l}$ ) and hyperglycaemia (16$20 \mathrm{mmol} / \mathrm{l})$. The number of patients with delayed emptying of the solid (S) and liquid (L) components of the meal is shown (from Fraser et al. [46])

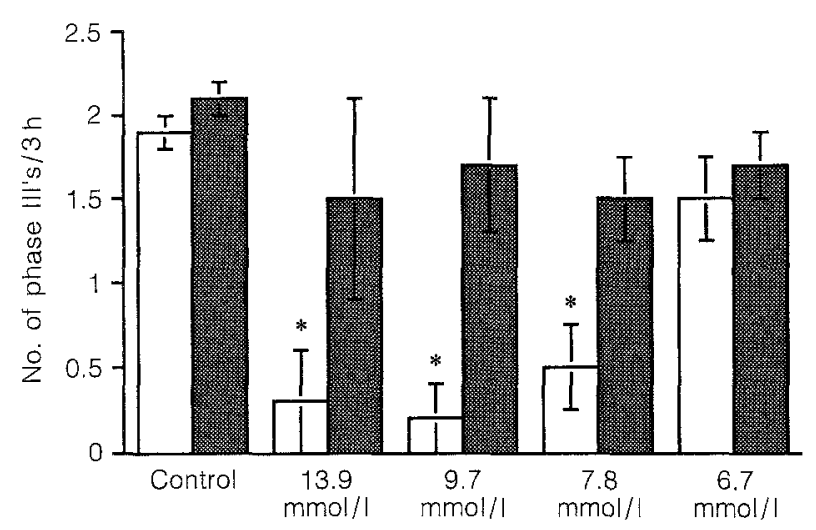

Fig.6. Effects of induced hyperglycaemia on the number of antral (open bars) and duodenal (shaded bars) phase 3 episodes during fasting in normal volunteers. Antral phase 3 is suppressed by plasma glucose concentrations as low as $7.8 \mathrm{mmol} / \mathrm{l}$, ${ }^{*} p<0.05$ compared to control period (from Barnett and Owyang [47])

frequently and that gastric motor dysfunctions are complex and variable $[14,35-40]$. A high prevalence of abnormal gastric electrical activity has been reported and may underlie the disordered motility [23]. In the fasted state phase 3 of the interdigestive motor complex in the stomach is characteristically absent, or reduced in frequency $[35,36]$. This is likely to account for delayed emptying of larger non-digestible solids and the recognized complication of bezoar formation. Postprandial antral hypomotility occurs frequently in patients with presumed gastroparesis $[14,36]$ and is likely to contribute to delayed emptying. A reduction in the number of antral pressure waves which are temporally associated with duodenal waves may be particularly important in this regard (Fig. 4) [38]. Although it has been reported that increased localized pyloric motility contributes to delayed emptying in diabetic gastroparesis [39], pyloric pressures were evaluated by an inadequate technique [1]. We found no evidence of an in- crease in either basal or phasic pyloric motor activity during euglycaemia [38], suggesting that increased pyloric resistance is unlikely to be a major factor contributing to retardation of transpyloric flow. Proximal small intestinal motility is frequently abnormal in diabetic patients with gastroparesis and may contribute to delayed emptying [36]. There have been no adequate studies of fundic motility in diabetes [12].

\section{Pathogenesis - impact of blood glucose concentration}

"Insulin alleviates motor abnormalities, even without resulting in hypoglycaemia." Ferroir (1937)

Gastroparesis and disordered gastric motility are more frequent in long-standing diabetes with other diabetic complications $[7,8,14]$ supporting the traditional belief that disordered gastric motility reflects irreversible vagal nerve damage [2]. However, there is a relatively poor correlation between gastric emptying and cardiovascular autonomic nerve dysfunction $[7,8]$. In animal models of diabetes, the neural innervation and neuropeptide content of the gastrointestinal tract is abnormal [41] and in preliminary human studies a decrease in the density of unmyelinated axons in the abdominal vagus was observed [42]. However, a more detailed study found no abnormalities in the gastric wall, or abdominal vagus in patients with diabetic gastroparesis [43]. Although this latter report was not comprehensive and the techniques used were relatively insensitive, it seems clear that the absolute number of neurones in the myenteric plexus is not reduced in diabetic gastroparesis. This observation is not unexpected and does not argue strongly against the concept that an irreversible defect in cholinergic function contributes in many cases to disordered gastric motility in diabetes. Further histological studies are required. The significance of hormonal changes to abnormal motility is uncertain. An increase in plasma motilin has been reported in patients with gastroparesis [35], but this has not been a consistent observation [40].

Recent studies indicate that the blood glucose concentration has a major influence on gastric motor function in diabetic patients and, possibly, in normal subjects [7, 44-48]. Gastric emptying in IDDM is slower during hyperglycaemia than during euglycaemia (Fig.5) [46] indicating that delayed gastric emptying does not always reflect "irreversible" autonomic neuropathy. This finding potentially has major implications in relation to nutrient absorption, the diagnosis of gastroparesis and the evaluation of the effects of pharmacological agents on gastric motility. An important, but unresolved issue is whether gastric emptying is affected by modest elevation of blood glucose within the physiological range, but the observation that fasting antral motility is suppressed by serum glucose levels as low as $7.8 \mathrm{mmol} / \mathrm{l}$ in normal subjects [47] supports this concept 
(Fig.6). The mechanism(s) by which hyperglycaemia slows gastric emptying are likely to be indirect. Alterations in vagal activity, gastric electrical activity, the secretion of gastrointestinal hormones (motilin, calcitonin gene-related peptide, glucagon, gastric inhibitory polypeptide) and myogenic mechanisms may all be important. Hyperglycaemia also affects motility in other regions of the gastrointestinal tract [48].

The motor mechanisms by which hyperglycaemia slows emptying have not been examined in diabetic patients. In normal subjects, induced hyperglycaemia decreases the number of antral pressure waves $[44,47]$, and stimulates localized pyloric pressure waves [44], a pattern of motility which is associated with retardation of transpyloric flow [1]. Hyperglycaemia is therefore likely to account, at least in part, for studies reporting reduced antral phase 3 activity, retention of non-digestible solids and increased localized pyloric pressure waves in patients with presumed gastroparesis $[14,36$, 39] in whom blood glucose was not monitored. In support of this concept, we have noted that transpyloric intubation is more easily achieved in diabetic patients if an elevated blood glucose concentration is normalised.

Gastrointestinal symptoms are a well-recognized feature of insulin-induced hypoglycaemia, but the effect of hypoglycaemia on gastrointestinal motility has received relatively little attention. In normal subjects hypoglycaemia has no effect on fasting pyloric pressures [49]. In a recent study, insulin-induced hypoglycaemia was reported to increase the rate of gastric emptying in IDDM, but the study design was suboptimal [50]. If confirmed, this effect may have major role in normalizing the blood glucose. It is possible that the presence of gastroparesis, or autonomic neuropathy is associated with an impaired gastric motor response to hypoglycaemia which could contribute to defective counter regulation of hypoglycaemia.

\section{Treatment}

Until the issue of whether pharmacological improvement in delayed gastric emptying, or "stabilization" of disordered emptying, results in better glycaemic control is resolved, the primary rationale for treatment is the occurrence of gastrointestinal symptoms attributable to disordered gastric motility. In asymptomatic patients with gastroparesis there is therefore at present no compelling indication for treatment. Before initiating therapy, other causes of gastroparesis, particularly reversible causes, such as electrolyte abnormalities, hypothyroidism, anorexia nervosa and drug side effects must be excluded [1]. The efficacy of dietary modifications (i. e. low fat, frequent meals and avoidance of nondigestible solids) has not been formally evaluated, but is often disappointing. Anecdotal reports suggest that improved blood glucose control may result in symptomatic improvement. A preliminary study reported that successful pancreatic transplantation may improve delayed gastric emptying [51]. The effect of aldose reductase inhibitors on gastric motility has not been evaluated. Antiemetic drugs such as prochlorperazine may provide some relief from nausea and vomiting, but are usually relatively ineffective and may exacerbate delay in gastric emptying because of their anticholinergic properties.

The outcome of present surgical treatments for diabetic gastroparesis is frequently unsatisfactory and may be associated with deterioration [1]. Surgery should only be performed in specialised centres when the patient has failed to respond to all other treatments. The choice of surgery may be influenced by measurements of gastric motility and the ability of the small intestine to handle a nutrient load. Surgical therapies for diabetic gastroparesis may improve with better understanding of pathophysiology. While electrical pacing of gastric muscle is technically possible, experience with this approach is much too limited for it to be considered. The most effective approach to the treatment of symptomatic patients with gastroparesis is the use of drugs designed to increase the rate of gastric emptying $[1,21]$. The heterogeneous nature of the motor dysfunctions in diabetic gastroparesis implies that it may be impossible to achieve correction of all motor/sensory abnormalities with one agent. The four prokineticdrugs that have been used widely to treat diabetic gastroparesis are metoclopramide $[18,52]$, domperidone $[23,53]$, cisapride $[11$, $19,20,54]$ and erythromycin [55]. Their pharmacological properties which lead to improvement in gastric emptying are poorly understood, but involve dopamine receptor blockade (domperidone and metoclopramide), stimulation of motilin receptors (erythromycin) and stimulation and blockade of subtypes of 5-hydroxytryptamine receptors (metoclopramide and cisapride) [1]. In most cases their use is associated with increased acetylcholine release from the gastric myenteric plexus. Metoclopramide (usual dose 10-20 mg orally four times a day) has central antiemetic properties and causes dose-related neurological side effects in up to $20 \%$ of patients. Domperidone (usual dose $10-20 \mathrm{mg}$ orally four times a day) is rarely associated with neurological side effects because it penetrates the blood-brain barrier poorly. Cisapride (usual dose $10 \mathrm{mg}$ four times a day) is generally very well tolerated. Erythromycin is well known to cause gastrointestinal side effects such as nausea, diarrhoea and abdominal cramps. Effects of erythromycin on gastric motility are dose-related [40] and acceleration of emptying occurs at doses of about $3 \mathrm{mg} / \mathrm{kg}$ i.v. or $250 \mathrm{mg}$ orally three times a day [55]. While infusions of motilin increase the rate of gastric emptying in diabetic gastroparesis [56] the short halflife precludes clinical use. Motilin agonists devoid of antibiotic activity, which have a longer duration of action are currently under development.

Single doses of all of these drugs increase gastric emptying in diabetic patients with gastroparesis $[1,21]$. 
In general, the magnitude of improvement is dose-related and greater when gastric emptying is more delayed $[1,54]$. There is relatively little information about the mechanical effects which are responsible for faster gastric emptying. Cisapride and erythromycin increase the number of antral, pyloric and duodenal pressure waves which are temporally related and suppress those pressure waves which are localised to the pylorus [40,57-59].

Although cisapride, domperidone and metoclopramide have been usually found to be more effective than placebo in improving symptoms $[21,52,53]$, this has not been a consistent observation $[11,22]$ and there is an absence of prolonged placebo-controlled cross-over studies. It is clear that there is only a weak, if any, relationship between effects on gastric emptying and the magnitude of symptomatic improvement $[19,20,53]$. The reason for this is uncertain. There have been few formal comparisons between drugs $[11,54]$ and the effect of the blood glucose concentration has generally not been accounted for in the evaluation of pharmacological therapies. The probability that certain drug combinations e.g. domperidone and cisapride may be synergistic has not been adequately addressed.

It is therefore not surprising that there is some dispute as to the optimal choice of prokinetic therapy $[1,21]$. There is some evidence that the gastrokinetic efficacy of metoclopramide [18, 52], domperidone [53] and erythromycin [55] diminishes during prolonged administration and this may account for symptom recurrence. Cisapride appears to have a sustained action $[20,60]$, is more potent than equivalent doses of metoclopramide [54] and is probably the agent of first choice at present. Metoclopramide and domperidone are useful alternatives, particularly because of their central antiemetic properties. There is limited information about the long-term effects of erythromycin, but the use of parenteral erythromycin ( $\sim 3 \mathrm{mg} / \mathrm{kg}$ i. v.) may be of particular value in the initial management of diabetic patients with severe nausea or vomiting and in facilitating the passage of transpyloric tubes. A single intravenous dose (200 mg i. v.) of erythromycin, the most potent of all the available drugs, makes emptying of a semisolid meal faster than normal in diabetic patients with gastroparesis [55]. Cisapride and domperidone are not available for parenteral use. When facilities for radioisotopic gastric emptying measurement are not available, prokinetic drugs may have to be given empirically. When a therapeutic trial is given, for perhaps 4 weeks, measurement of gastric emptying must be performed if symptoms persist, or if they recur following cessation of therapy. No studies have evaluated whether prokinetic therapy is useful in diabetic patients who have significant upper gastrointestinal symptoms, but normal gastric emptying.

Despite improvements in pharmacotherapy treatment of gastrointestinal symptoms in diabetic patients is not uniformly satisfactory $[1,21]$ and there is a need for new therapeutic approaches. Pharmacological modification of sensory feedback from the gastrointestinal tract represents an area of considerable research activity and is likely to be a useful therapeutic approach to the management of gastrointestinal symptoms. Antagonists of serotonin $\left(5 \mathrm{HT}_{3}\right)$ receptors and opiates show particular promise in this regard [1]. The role of biofeedback techniques (such as the use of gastric distension) in the treatment of symptomatic gastroparesis also warrants evaluation.

\section{Conclusions}

The application of novel investigative techniques has contributed to an increased understanding of the prevalence, pathophysiology and treatment of disordered gastric motility in diabetes. Abnormal gastric emptying, particularly delayed emptying, occurs frequently and the rate of gastric emptying is influenced by the blood glucose concentration. Disordered gastric motility is likely to be responsible for most upper gastrointestinal symptoms in diabetic patients, but the mechanisms by which abnormal motility leads to symptoms are poorly understood. It appears probable that abnormal gastric emptying contributes to poor glycaemic control. Gastrokinetic drugs have improved therapeutic options for symptomatic patients with gastroparesis considerably. Future approaches to modulate gastric and small intestinal sensory responses may lead to significant advances in treatment.

Acknowledgements. Our work in this area has been supported by grants from the National Health and Medical Research Council of Australia and the Rebecca L. Cooper Medical Research Foundation Ltd. We wish to thank Ms. T.Piscioneri and Ms. S. Suter for typing the manuscript.

\section{References}

1. Horowitz M, Dent J (1991) Disordered gastric emptying: mechanical basis, assessment and treatment. Bailliere's Clin Gastroenterol 5:371-407

2. Rundles RW (1945) Diabetic neuropathy; general review with report of 125 cases. Medicine 24: $111-160$

3. Saltzman MA, McCallum RW (1983) Diabetes and the stomach. Yale J Biol Med 56: 179-187

4. Kassander P (1958) Asymptomatic gastric retention in diabetics (gastroparesis diabeticorum). Ann Int Med 48: $797-812$

5. Zitomer BR, Gramm HF, Kozak GP (1968) Gastric neuropathy in diabetes mellitus. Clinical and radiological observations. Metabolism 17: 199-211

6. Horowitz M, Harding PE, Maddox A et al. (1989) Gastric and oesophageal emptying in patients with type 2 (non-insulin-dependent) diabetes mellitus. Diabetologia 32: 151159

7. Horowitz M, Maddox AF, Wishart JM, Harding PE, Chatterton BE, Shearman DJC (1991) Relationships between oesophageal transit and solid and liquid gastric emptying in diabetes mellitus. Eur J Nucl Med 18:229-234 
8. Wegener M, Börsch G, Schaffstein J, Luerweg C, Leverkus F (1990) Gastrointestinal transit disorders in patients with insulin-treated diabetes mellitus. Dig Dis 8: 23-26

9. Keshavarzian A, Iber FL, Vaeth J (1987) Gastric emptying in patients with insulin-requiring diabetes mellitus. Am J Gastroenterol 82: 29-35

10. Urbain JL, Vekemans MC, Bouillon R et al. (1993) Characterization of gastric antral motility disturbances in diabetes using a scintigraphic technique. J Nucl Med 34: 576-581

11. De Caestecker JS, Ewing DJ, Tothill P, Clarke BF, Heading RC (1989) Evaluation of oral cisapride and metoclopramide in diabetic autonomic neuropathy: an eight week doubleblind crossover study. Aliment Pharmacol Ther 3: 69-81

12. Oliveira RB, Troncon LEA, Meneghelli UG, Dantas RO, Godoy RA (1984) Gastric accomodation to distension and early gastric emptying in diabetics with neuropathy. Braz J Med Biol Res 17: 49-55

13. Phillips WT, Schwartz JG, McMahon CA (1992) Rapid gastric emptying of an oral glucose solution in type 2 diabetic patients. J Nucl Med 33: 1496-1500

14. Kim CH, Kennedy FP, Camilleri M, Zinsmeister AR, Ballard DJ (1991) The relationship between clinical factors and gastrointestinal dysmotility in diabetes mellitus. J Gastroint Motil 3: 268-272

15. Chaudhuri TK, Fink S (1992) Prognostic implications of gastroparesis in patients with diabetes mellitus. Clin Autonom Res 2: 221-224

16. Feldman M, Schiller LR (1983) Disorders of gastrointestinal motility associated with diabetes mellitus. Ann Int Med 98: 378-384

17. Clouse RE, Lustman PJ (1989) Gastrointestinal symptoms in diabetic patients: lack of association with neuropathy. Am J Gastroenterol 84: 868-872

18. Loo FD, Palmer DW, Soergel KH, Kalbfleisch JH, Wood CM (1984) Gastric emptying in patients with diabetes mellitus. Gastroenterology 86: 485-494

19. Horowitz M, Maddox A, Harding PE et al. (1987) Effects of cisapride on gastric and esophageal emptying in insulin-dependent diabetes mellitus. Gastroenterology 92: 1899-1907

20. Camilleri M, Malagelada J-R, Abell TL, Brown ML, Hench V, Zinsmeister AR (1989) Effect of six weeks of treatment with cisapride in gastroparesis and intestinal pseudo-obstruction. Gastroenterology 96: 704-712

21. Drenth JPH, Engels LGJB (1992) Diabetic gastroparesis. A critical appraisal of new treatment strategies. Drugs 44: 537553

22. Havelund T, Oster-Jorgensen E, Eshaj O, Larsen ML, Lauritsen K (1987) Effects of cisapride on gastroparesis in patients with insulin-dependent diabetes mellitus. A doubleblind controlled trial. Acta Med Scand 222: 339-343

23. Koch KL, Stern RM, Stewart WR, Vasey MW (1989) Gastric emptying and gastric myoelectrical activity in patients with diabetic gastroparesis: effect of long-term domperidone. Am J Gastroenterol 84: 69-75

24. Mearin F, Cucala M, Azpiroz F, Malagelada J-R (1991) The origin of symptoms in the brain-gut axis in functional dyspepsia. Gastroenterology 101: 999-1006

25. Horowitz M, Edelbroek MAL, Wishart J, Straathof J (1993) Relationship between oral glucose tolerance and gastric emptying in normal healthy subjects. Diabetologia 36: 857862

26. Blair EH, Wing RR, Wald A (1991) The effect of laboratory stressors on glycemic control and gastrointestinal transit time. Psychosomatic Medicine 53: 133-143

27. Fried M, Schwizer W, Beglinger C, Keller U, Jansen JB, Lamers CB (1991) Physiological role of cholecystokinin on postprandial insulin secretion and gastric meal emptying in man. Studies with the cholecystokinin receptor antagonist loxiglumide. Diabetologia 34: 721-726

28. Mourot J, Thouvenot P, Couet C, Antoine JM, Krobicka A, Debry G (1988) Relationship between the rate of gastric emptying and glucose and insulin responses to starchy foods in young healthy adults. Am J Clin Nutr 48: 1035-1040

29. Torsdottir I, Alpsten M, Holm G, Sandberg AS, Tolli J (1991) A small dose of soluble alginate-fiber affects postprandial glycaemia and gastric emptying in humans with diabetes. $\mathbf{J}$ Nutr 121: 795-799

30. Phillips WT, Schwarz JG, McMahon CA (1993) Reduced postprandial blood glucose levels in recently diagnosed noninsulin-dependent diabetics secondary to pharmacologically induced delayed gastric emptying. Dig Dis Sci 38: 51-58

31. Cunningham KM, Horowitz M, Read NW (1991) The effect of short-term dietary supplementation with glucose on gastric emptying in humans. Brit J Nutrit 65: 15-19

32. Edelbroek M, Horowitz M, Fraser R et al. (1992) Adaptive changes in the pyloric motor response to intraduodenal dextrose in normal subjects. Gastroenterology 103: 1754-1761

33. O'Connell ME, Awni WM, Goodman M et al. (1987) Bioavailability and disposition of metoclopramide after single- and multiple-dose administration in diabetic patients with gastroparesis. J Clin Pharmacol 27: 610-614

34. Groop LC, De Fronzo RA, Luizi L, Melander A (1989) Hyperglycaemia and absorption of sulphonylurea drugs. Lancet II: $129-130$

35. Achem-Karam SR, Funakoshi A, Vinik AI, Owyang C (1985) Plasma motilin concentration and interdigestive migrating motor complex in diabetic gastroparesis: effect of metoclopramide. Gastroenterology 88: 492-499

36. Camilleri M, Malagelada J-R (1984) Abnormal intestinal motility in diabetics with the gastroparesis syndrome. Eur J Clin Invest 14: 420-427

37. Feldman M, Smith HJ (1987) Effect of cisapride on gastric emptying of indigestible solids in patients with gastroparesis diabeticorum: a comparison with metoclopramide and placebo. Gastroenterology 92: 171-174

38. Fraser R, Horowitz M, Maddox A, Dent J (1993) Organization of antral, pyloric and duodenal motility in patients with gastroparesis. J Gastroint Motil 5: 167-175

39. Mearin F, Camilleri M, Malagelada J-R (1986) Pyloric dysfunction in diabetics with recurrent nausea and vomiting. Gastroenterology 90: 1919-1925

40. Tack J, Janssens J, Vantrappen G et al. (1992) Effect of erythromycin on gastric motility in controls and in diabetic gastroparesis. Gastroenterology 103: 72-79

41. Soediono P, Belai A, Burnstock G (1993) Prevention of neuropathy in the pyloric sphincter of streptozotocin-diabetic rats by gangliosides. Gastroenterology 104: 1072-1082

42. Guy RJC, Dawson JL, Garrett JR, Laws JW, Thomas PK, Sharma AK (1984) Diabetic gastroparesis from autonomic neuropathy: surgical considerations and changes in vagus nerve morphology. J Neurol Neurosurg Psych 47: 686-691.

43. Yoshida MM, Schuffer MD, Sumi SM (1988) There are no morphologic abnormalities of the gastric wall or abdominal vagus in patients with diabetic gastroparesis. Gastroenterology 94: 907-914

44. Fraser R, Horowitz M, Dent J (1991) Hyperglycaemia stimulates pyloric motility in normal subjects. Gut 32:475-478

45. Oster-Jorgensen E, Pedersen SA, Larsen ML (1990) The influence of induced hyperglycaemia on gastric emptying in healthy humans. Scand J Clin Lab Invest 50: 831-836

46. Fraser R, Horowitz M, Maddox AF, Harding PE, Chatterton BE, Dent J (1990) Hyperglycaemia slows gastric emptying in type 1 (insulin-dependent) diabetes mellitus. Diabetologia 30: $675-680$ 
47. Barnett JL, Owyang C (1988) Serum glucose concentration as a modulator of interdigestive gastric motility. Gastroenterology 94: 739-744

48. de Boer SY, Masclee AAM, Lam WF, Lamers CBHW (1992) Effect of acute hyperglycemia on esophageal motility and lower esophageal sphincter pressure in humans. Gastroenterology 103: 775-780

49. Fraser R, Fuller J, Horowitz M, Dent J (1991) The effect of insulin-induced hypoglycaemia on fasting antral, pyloric and duodenal motility. Clin Sci 81: 281-285

50. Schvarcz E, Palmer M, Aman J, Lindkvist B, Beckman K-W (1993) Hypoglycaemia increases gastric emptying rate in patients with insulin-dependent diabetes mellitus. Diab Med 10: 660-663

51. Gaber A, Oxley D, Karas J et al. (1991) Changes in gastric emptying in recipients of successful combined pancreas-kidney transplants. Dig Dis 9: 437-443

52. Schade RR, Dugas MC, Lhotsky DM, Gavaler JS, Van Thiel $\mathrm{DH}$ (1985) Effect of metoclopramide on gastric liquid emptying in patients with diabetic gastroparesis. Dig Dis Sci 30: $10-15$

53. Horowitz M, Harding PE, Chatterton BE, Collins PJ, Shearman DJC (1985) Acute and chronic effects of domperidone on gastric emptying in diabetic autonomic neuropathy. Dig Dis Sci 30: 1-9

54. McHugh S, Lico S, Diamant NE (1992) Cisapride vs metoclopramide. An acute study in diabetic gastroparesis. Dig Dis Sci 37: 997-1001

55. Janssens J, Peeters TL, Vantrappen G et al. (1990) Improvement in gastric emptying in diabetic gastroparesis by erythromycin. New Engl J Med 322: 1028-1031

56. Schmid R, Schusdziarra V, Allescher HD, Bofilias I, Buttermann G, Classen M (1991) Effect of motilin on gastric emptying in patients with diabetic gastroparesis. Diabetes Care 14: $65-68$

57. Fraser R, Shearer T, Fuller J, Horowitz M, Dent J (1992) Intravenous erythromycin overcomes small intestinal feedback on antral, pyloric and duodenal motility. Gastroenterology 103: 114-119

58. Fraser R, Horowitz M, Maddox A, Dent J (1994) Postprandial antropyloroduodenal motility and gastric emptying in gastroparesis - effects of cisapride. Gut 35: 172-178

59. Fraser R, Horowitz M, Maddox A, Dent J (1993) Dual effects of cisapride on gastric emptying and antropyloroduodenal motility. Am J Physiol 264: G195-G201

60. Horowitz M, Roberts A (1990) Long term efficacy of cisapride in diabetic gastroparesis. Am J Med 88: 195-196 